\title{
AC 2011-1934: SHIFTING TO A STUDENT-FOCUSED INTRODUCTORY COURSE FOR FRESHMAN STUDENTS
}

\author{
Kristi J Shryock, Texas A\&M University
}

Kristi J. Shryock is a Lecturer and Director of Undergraduate Programs in the Department of Aerospace Engineering at Texas A\&M University. She received both a B.S. and M.S. in Aerospace Engineering from Texas A\&M and received her Ph.D. in Interdisciplinary Engineering at Texas A\&M in May 2011. Her research work focuses on engineering education.

\section{Dr. Dimitris C. Lagoudas, Texas A\&M University}

D. C. Lagoudas currently is the Department Head and the inaugural recipient of the John and Bea Slattery Chair in Aerospace Engineering at Texas A\&M University. He also serves as the Director for the Texas Institute for Intelligent Materials and Structures (TiiMS). His research involves the design, characterization and modeling of multifunctional material systems at nano, micro and macro levels. During the past two decades he has published extensively on the subject of shape memory alloys with his students, postdoctoral associates and colleagues and several of his journal papers are now considered classic papers in the field. He served as an Associate Vice President for Research for Texas A\&M University from 20012004, and as the first chair of the Materials Science and Engineering Program at TAMU. He has been involved with curriculum innovations and engineering education throughout his career, notably with the Foundation Coalition, where he focused on restructuring the sophomore year engineering curriculum.

\section{Julie J. Parish, Texas A\&M University}

Julie J. Parish is a Ph.D. student in the Department of Aerospace Engineering at Texas A\&M University. Her current research investigates strategies for exploiting the structure of the governing differential equations of constrained and hybrid dynamical systems for state estimation. She is the recipient of the NSF Graduate Research Fellowship, NDSEG Graduate Research Fellowship, and AIAA Orville and Wilbur Wright Graduate Student Award. 


\title{
Shifting to a Student-Focused Introductory Course for Freshman Students
}

\begin{abstract}
In this paper, modifications made to a first-year introductory aerospace engineering course are outlined. The original seminar-based course has been revised to better engage freshman students and connect them to the aerospace department community through guest lectures, field trips, assignments, and upperclassmen mentoring. The changes to this course were motivated by a desire to increase the retention of students from the freshman to the sophomore year. Here, attitudinal survey results from students participating in the course are discussed, as well as a research plan for analyzing the effectiveness of the course adjustments.
\end{abstract}

\section{Introduction}

The problem of retaining students is pervasive throughout all of the engineering disciplines. ${ }^{1,2}$ Within the aerospace community, the impact of an aging workforce is a cause for alarm with respect to both the national economy and national security. ${ }^{3}$ Several U.S. government commission reports have investigated the problem, one observing ${ }^{4,5}$ :

The industry is confronted with a graying workforce in science, engineering and manufacturing, with an estimated 26 percent available for retirement within the next five years... Clearly, there is a major workforce crisis in the aerospace industry. Our nation has lost over 600,000 scientific and technical aerospace jobs in the past 13 years [2002].

In the Department of Aerospace Engineering at Texas A\&M University, six-year graduation rates were only $20 \%$ for 2007 . The biggest drop in retention rate was found to occur from the freshman to sophomore year, where students were only exposed to general engineering courses outside of the department without any instruction in aerospace-specific applications or design problems. Several factors have been cited as reasons for the decline in retention of university students in aerospace engineering. Students that have chosen to leave the department were interviewed and listed several reasons for leaving aerospace engineering, including the beliefs that:

1. Aerospace engineering is too narrow a discipline

2. Aerospace engineering is no longer relevant

3. Aerospace engineering is more difficult than other engineering disciplines

4. There are no jobs in aerospace engineering

5. One can do aerospace engineering with a degree in another engineering discipline

Echoed in these beliefs, the general loss of enthusiasm for the aerospace industry is an area of specific concern. Students accepted to the department are generally already attracted to the prospect of a career in the aerospace industry, and the goal of the freshman introductory course Principles of Aerospace Engineering (AERO 101) is to encourage and nurture this interest. Because Texas A\&M University is a very large institution, working to make students feel 
connected to the department and excited to join the community is a significant aspect of this effort. $^{6}$

In the past, the department has conducted Principles of Aerospace Engineering as a seminar course limited to a one-way exchange of information about the field of aerospace engineering. That is, once a week, students listened to a different professor or industry member speak on a particular topic or their company, but interaction with students was limited. Furthermore, the material was often too technical for the freshman level.

In spring 2009, the institution decided to change the focus of the course to encourage student participation through more engaging classes and a new design component. Instead of viewgraph presentations, guest speakers were asked to bring in demonstrations to explain current aerospace design problems and applications of new technology. Industry representatives were invited to present "real-world" problems they are resolving to give students a better appreciation of the unique challenges of the aerospace industry. Also, aerospace student organizations, graduate students, and upperclassmen were recruited to speak to the students about research opportunities, aspects of senior design projects, and ways to become involved in the aerospace community to encourage integration of students into the department after their freshman year.

The course has continued to evolve with the addition of a freshman mentoring program in the fall of 2010. This addition to the course sought to connect junior and senior level students to freshman students in the department to give freshman students a resource for advice on classes, instructors, study habits, career options, research, student organizations, and general college life. The mentors have also functioned as a source of encouragement by providing insight about how fundamental classes support interesting upper-level coursework and by coaching the freshmen through the learning curves of the first-year math and science classes.

This paper describes in detail the new structure of this introductory course. Class topics are divided into three broad areas to give first year students both a broad understanding of the field and a working knowledge of how their collegiate experience might shape their long-term career plans. The first section of the course is focused on familiarizing students with the three primary disciplines of aerospace engineering. These activities, presented by department faculty and graduate students, are designed to introduce relevant, interesting problems to the class that relate their foundational freshmen coursework to both upper-level coursework and current research. The second area of the course emphasizes opportunities for students to become immediately involved in the aerospace community. Undergraduate research opportunities and programs are presented with examples from upperclassmen, and aerospace student organizations are invited to class to introduce their missions and activities. The final area included in the curriculum concerns career opportunities. Here, activities are prepared to help students better understand the broad range of career options available in the aerospace industry and how to prepare for an employment search. To support each of these topics, students are given both individual and team assignments to engage them in critical thinking about aerospace engineering problems. Furthermore, each of these components is supplemented by a mentoring program session with an assignment that reflects the content of the component.

These three parts of the curriculum for Principles of Aerospace Engineering are presented with supporting assignment examples in the Appendix. The attitudinal survey results and related 
observations from fall 2010 AERO 101 students follow each of the three areas. Finally, the mentoring program is more fully described and its effectiveness discussed. Future work regarding assessment of the effectiveness of the course changes and new ideas for the class concludes the paper.

\section{The Aerospace Disciplines}

At Texas A\&M University, the Department of Aerospace Engineering is subdivided into three primary disciplines: aerofluids and propulsion, materials and structures, and dynamics and control. The first component of the course curriculum seeks to introduce students to these areas and associate them with their existing notions of aerospace engineering. First, an overview of the history of aerospace engineering is presented. The highlights of this presentation-great engineering feats such as manned space missions - are then related to the relevant freshman and upper-level aerospace engineering courses that contribute to understanding that system.

Subsequent presentations that focus on each of the three disciplines are given by faculty members specializing in that area. These guest lecturers are specifically chosen for their combination of enthusiasm for their discipline and rapport with undergraduate students. Here, the intent is to encourage the freshman students to better connect with the department and feel encouraged to continue to their aerospace-specific engineering coursework. Prior to each of these presentations, students are given either individual or group projects that provide background information and critical thinking exercises to help them to be more technically receptive to the material presented.

An example of the "materials and structures" assignment is given in the Appendix. Note that the purpose of the assignment is laid out for the students, and that the focus of the assignment is thinking critically about technical topics, rather than explicitly applying technical engineering skills. When asked, "In which assignments did you learn the most?" students most often cited the assignments related to the aerospace discipline. From student comments, this was likely because these assignments challenged a preconceived notion or introduced a new engineering concept. Figure 1 shows the attitudinal results related to the aerospace engineering disciplines from the end of semester survey. Students were asked: 
Please rate the different activities in Principles of Aerospace Engineering based on how effective they are in contributing to your understanding of Aerospace Engineering and/or connecting you with the Aerospace Department.

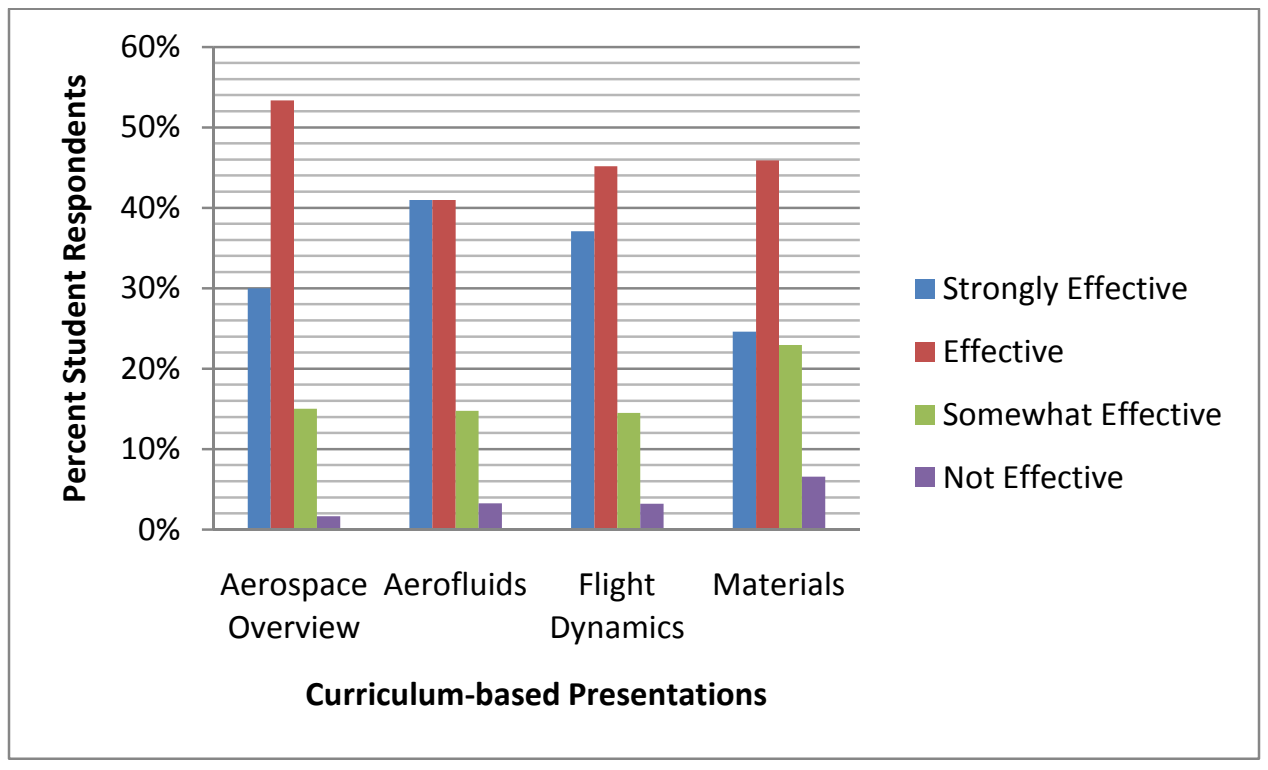

Figure 1: Technical Discipline Survey Results

Contrary to our initial expectations, the curriculum-based presentations were, on average, more highly rated than some of the more interactive experiences, such as the space robotics lab tour with live hands-on lab demonstrations. This result was unexpected due to the poorer reception of the aforementioned seminar-only class by past freshman classes. One recommendation is to keep this part of the class as is-presentations condensed to a less technical overview that aim to engage but not overwhelm first year students.

\section{Undergraduate Opportunities in Aerospace}

The second area of emphasis in this introductory course is presenting opportunities for undergraduate students to get involved in professional societies, design teams, or research. To introduce students to organizations such as the American Institute of Aeronautics and Astronautics (AIAA) or projects such as the Society of Automotive Engineers (SAE) Aerodesign Team, officers from these groups visit the class to present activities, benefits, and membership requirements of their organization. Undergraduate research opportunities, such as summer grants, honors projects, or part-time employment, are presented separately over several classes. A combination of professors, graduate students, and undergraduates hosted tours of research facilities and discussed past and current research projects. 
At the end of the semester, students were again asked to rate the effectiveness of these activities, shown below in Fig. 2.

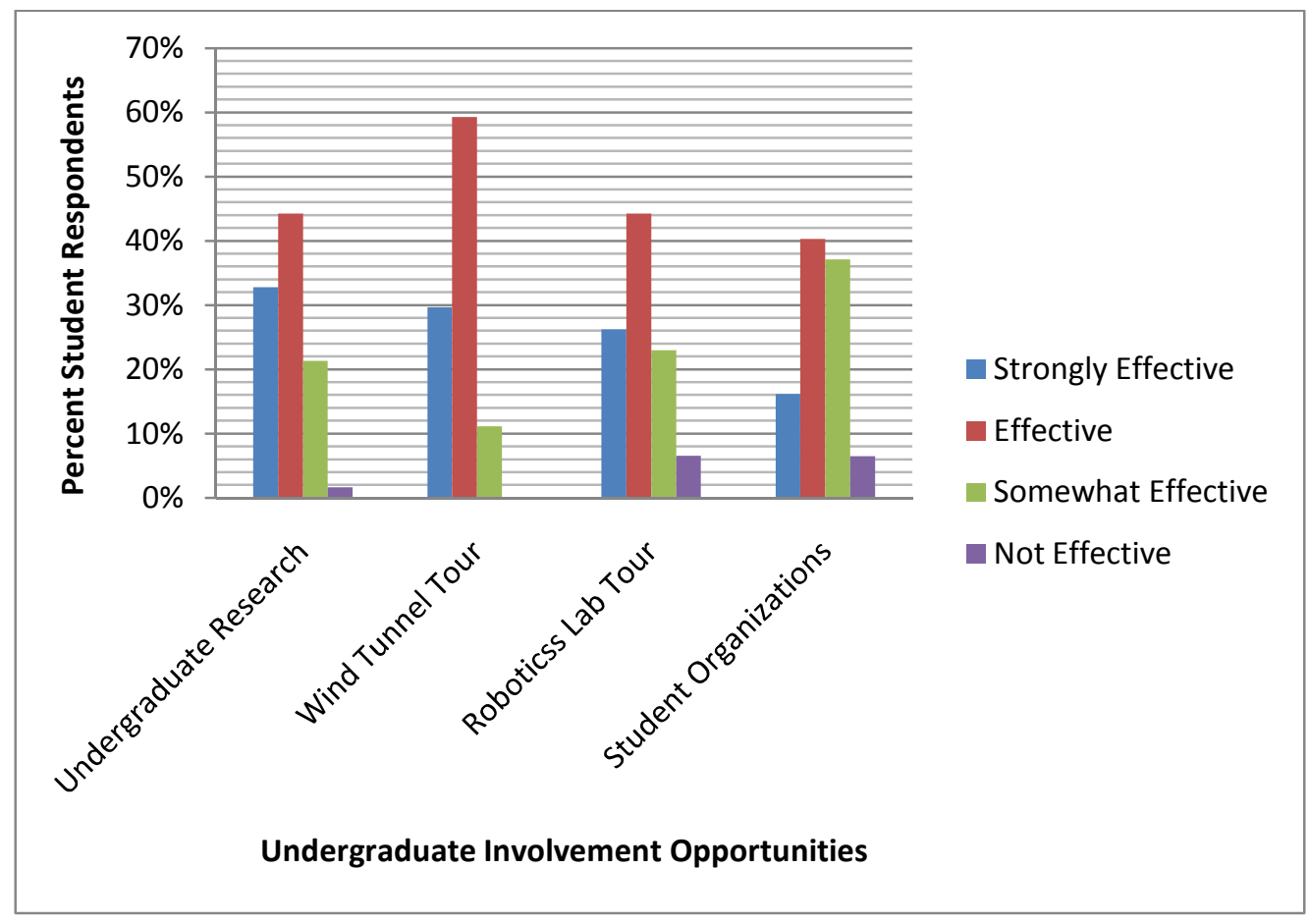

Figure 2: Undergraduate Opportunities Survey Results

Note that not all students were required to attend the wind tunnel tour, whereas the robotics lab tour was mandatory. Consequently, a better practice may be to have students choose one or two tours to attend from a list in order to tailor these activities more to their interests. The student organizations presentation appears to be least effective; additional student comments indicated that much of this information was available elsewhere, and therefore not as helpful.

\section{Career Opportunities}

As a primary motivator in successfully completing a degree in aerospace engineering is postgraduate employment in the industry, a significant portion of the course curriculum is focused on helping students navigate career options. In general, this information is split into three areascareers in industry, government, and academia. Employment opportunities in industry and government are more specifically addressed, as graduate school/research is well coupled with the aforementioned undergraduate research activities. At this time entrepreneurship is not specifically addressed, but may be incorporated into future classes if the aerospace industry emphasis on space commercialization continues to grow.

Students were exposed to potential career routes through a career fair assignment, guest speakers, and a semester-end industry tour. As the career fair for this university occurs early in each fall and spring semester, the career fair assignment was the first exposure to potential employment options for most students. The assignment (see Appendix) briefly led students through the process of researching which companies are attending the career fair and encouraging them to think about what kinds of projects on which they might want to work if they 
were seeking full-time employment. Furthermore, students were asked to physically visit the event to observe how recruiters interact with potential employees. The goal of this assignment was to give first year students a more concrete picture of what type of work they might perform in the aerospace industry and the breadth of employment options available.

Guest speakers from both government and industry were invited inside the classroom to discuss their actual work, career path, and opportunities with their employer. As a reflection of U.S. government involvement in aerospace, a NASA astronaut presented a seminar and reflected on how aerospace engineers at both NASA and supporting industry contractors are shaping the future of space exploration. The speaker also addressed concerns about the future of U.S. government investment in space programs. Another guest speaker specifically outlined the coop program at their organization, which provided an opportunity to discuss, in general, internship and co-op options in the aerospace engineering. Furthermore, the student panel, discussed later in this paper, gave upper-level students the opportunity to speak about their own internship, coop, and employment search experiences.

The semester-long Principles of Aerospace Engineering course concludes with a day trip for an on-site tour of an aerospace engineering company. During this trip, practicing aerospace engineers present to the students about the projects on which they are currently working, and then show the students actual experimental or production facilities. Students interact directly with several aerospace engineering graduates from Texas A\&M University and have the opportunity to ask questions about future employment opportunities and preparation for becoming a successful candidate for these careers.

As with the other areas of the course, student attitudes as to the effectiveness of these activities were surveyed at the end of the semester. Note that most, but not all, students attended the industry tour.

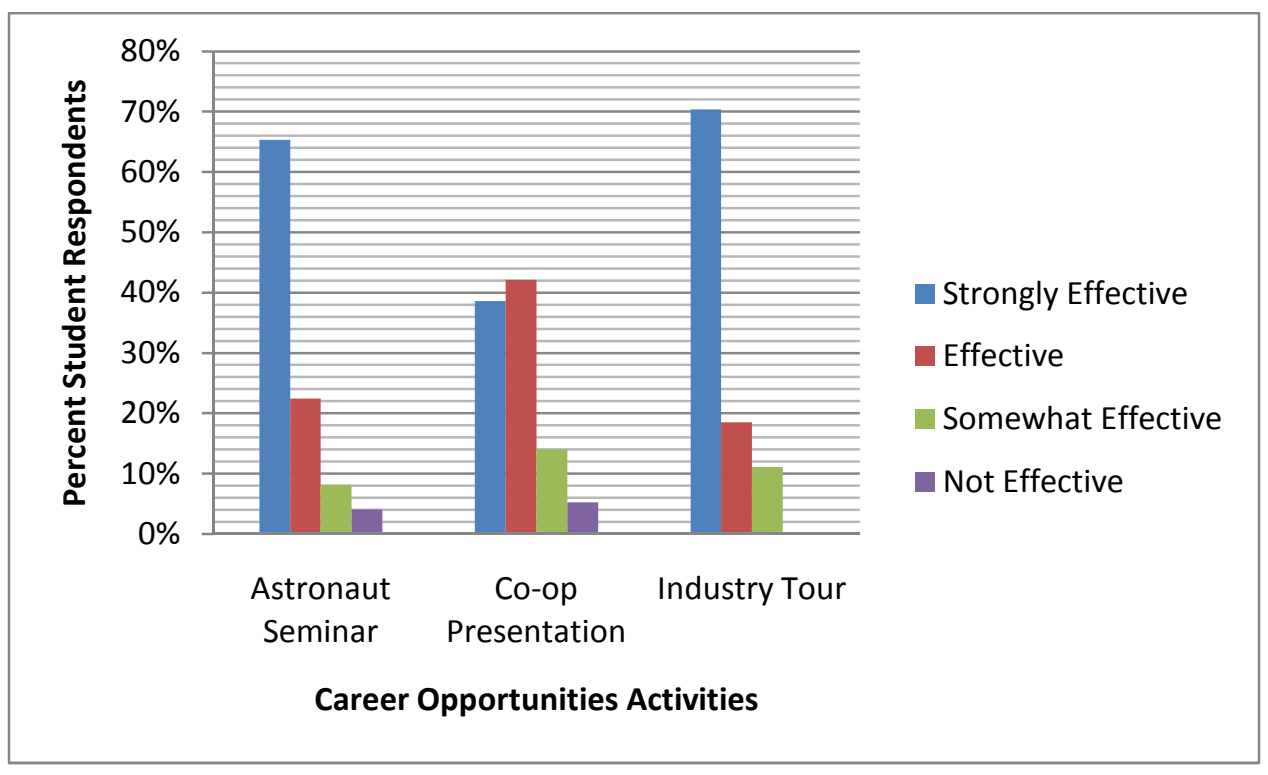

Figure 3: Career Opportunities Survey Results 
The results in Fig. 3 show that, perhaps more than any other activity, students felt that the seminar given by a NASA astronaut was most effective at engaging their interest in aerospace engineering. The personal experience and emphasis of this presentation on the great achievement of manned space missions by past aerospace engineers likely contributed to this strong attitude of the students. The industry tour was likewise well received and will be continued in future semesters. Unlike many of the university-centered undergraduate opportunities in aerospace, described previously, the co-op presentation was considered very effective by students. Perhaps less familiarity with these opportunities was an attributing factor; more emphasis on immediate career opportunities, both co-ops and internships, ought to be incorporated into future semesters.

\section{Upperclassmen Mentoring Program}

The addition of a new mentoring aspect to the course was an intentional effort to give students a better sense of community with the aerospace department. Upperclassman volunteers from the aerospace engineering honor society were assigned to a group of approximately four freshmen. Through several meetings scheduled throughout the semester, the groups were given the opportunity to discuss the respective curriculum areas (aerospace disciplines/coursework, opportunities for aerospace community involvement, and career advice). Several "icebreaker" questions were provided to the students to help them get to know both their group members and their mentor.

In addition to these one-on-four activities, a student panel with approximately six upper-level undergraduates and two graduate students was organized to field questions from the class. Most of the questions asked pertained to class schedules, internships, employment offers/searches, and work/life balance. Of the two types of mentor activities, the panel was deemed on average more effective by the freshman students, as show below in Fig. 4.

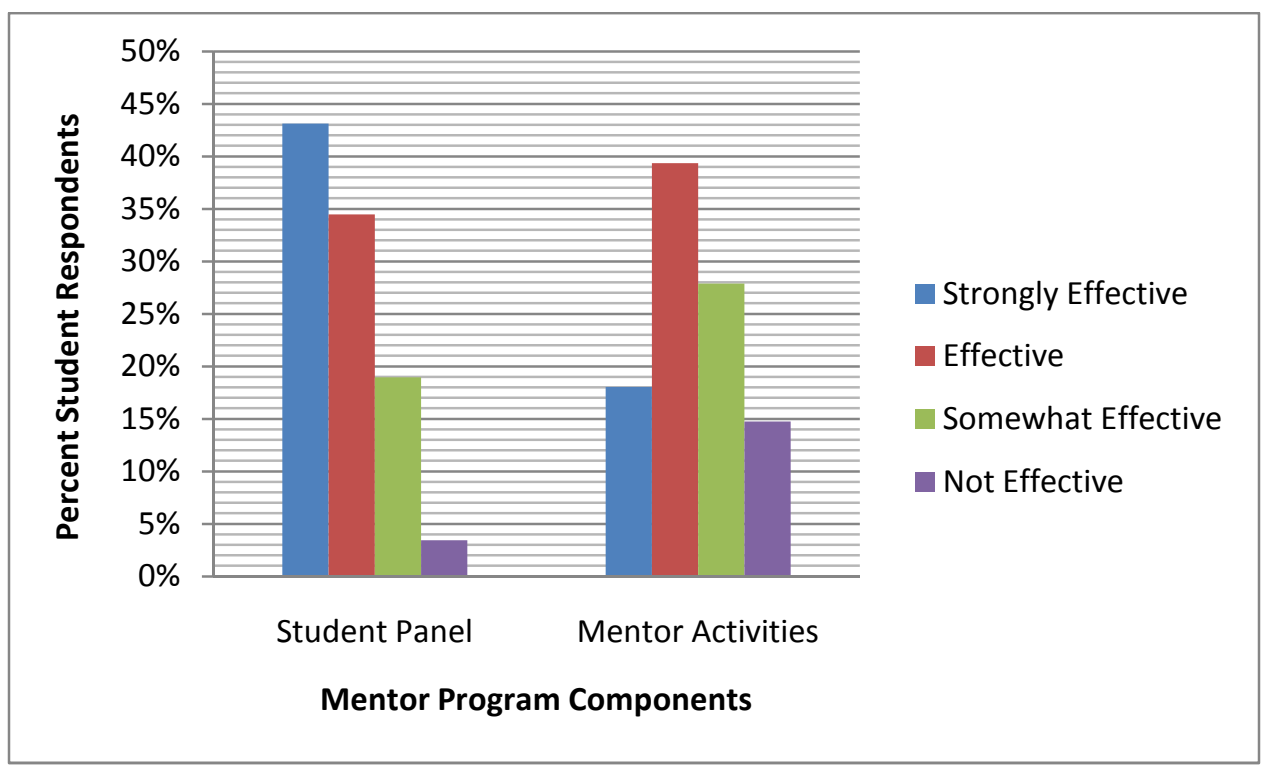

Figure 4: Mentor Program Survey Results 
The qualitative comments from the student surveys indicated a strong correlation between the effectiveness of the mentoring one-on-four sessions and their perceived quality of the mentor assigned to the group. In light of these comments, one recommendation is to approach specific candidates to serve the students of future classes. The survey comments also noted that the panel and mentoring sessions gave students the opportunity to ask honest advice and insight from their peers about the freshman coursework and how it contributes to later aerospace engineering curriculum. Moving the one-on-four mentor meetings outside of the classroom may allow first year students to feel even more comfortable asking frank questions and receiving honest feedback from their mentors.

\section{Course Outcome Results}

The modifications to shift Principles of Aerospace Engineering to a more student-focused experience intended to motivate incoming students and consequently increase the retention of these students into the sophomore year, where aerospace engineering curriculum replaces the freshman foundational engineering curriculum.

The final survey questions for the fall 2010 class addressed the course outcomes-the overall efficacy of the course and student attitudes toward their potential success in completing the degree program:

From Principles of Aerospace Engineering:

- I gained a better understanding of aerospace applications.

- I gained a better understanding of aerospace career opportunities.

- I felt more motivated to stay in aerospace engineering.

- I felt more connected with the aerospace department.

- Overall, I was satisfied with the activities and lectures in AERO 101.

The associated survey results in Fig. 5 clearly show that, though the students seem satisfied with the course and successfully gained a better understanding of the types of problems and careers associated with the aerospace industry, the introductory course was less successful in motivating them to stay in the department. 


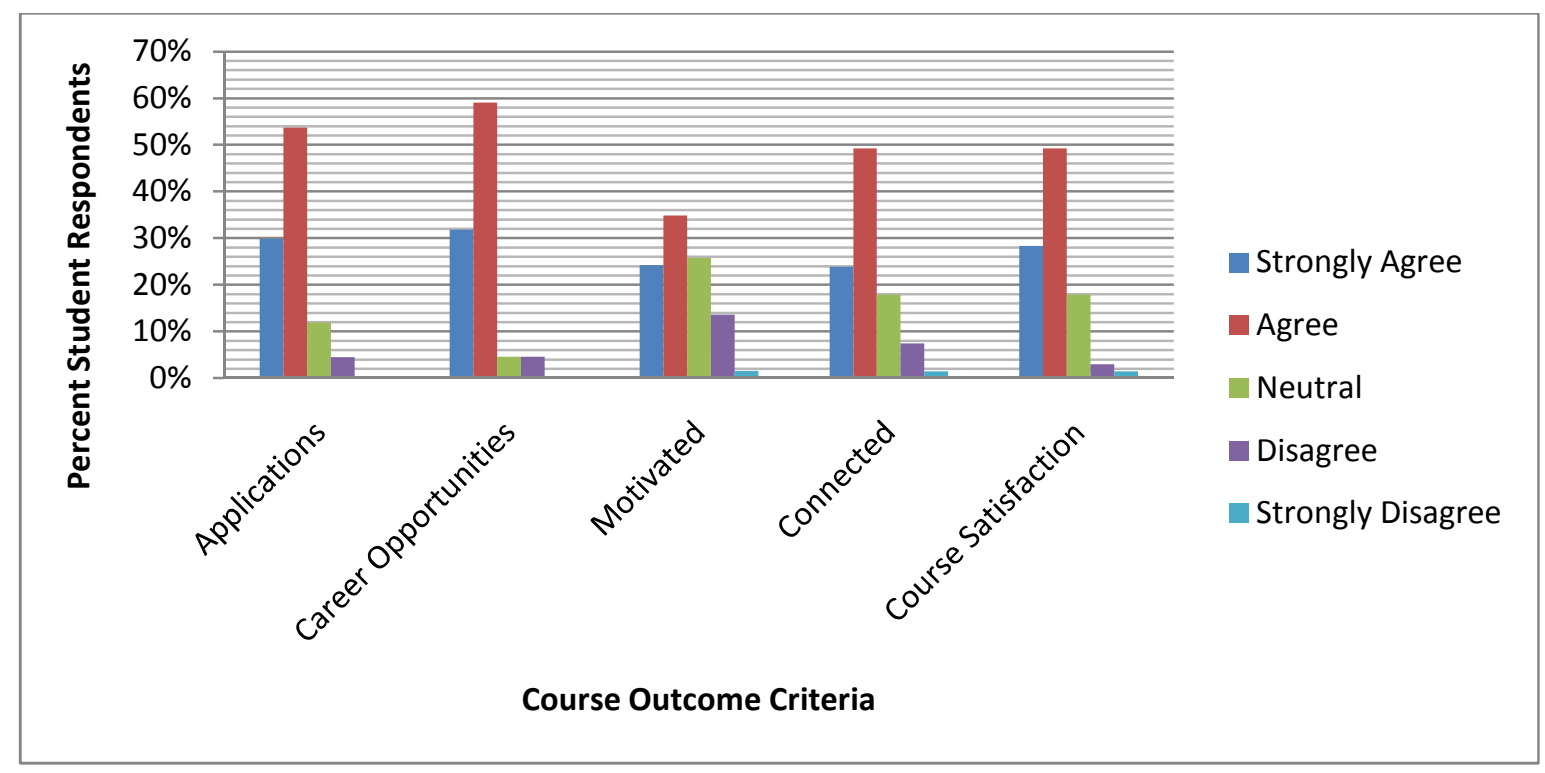

Figure 5: Course Outcome Survey Results

However, survey responses were very positive to the following statement, which did not directly refer to AERO 101:

I am confident I will succeed in the undergraduate Aerospace Engineering program.

These results are shown in Fig. 6. The discrepancy between the responses to the "motivated" and "confident" questions may either be related to whether a student respectively "will choose to" or "can" complete the aerospace engineering program, or may simply indicate that students do not feel that the introductory course is a strong factor motivating their decision.

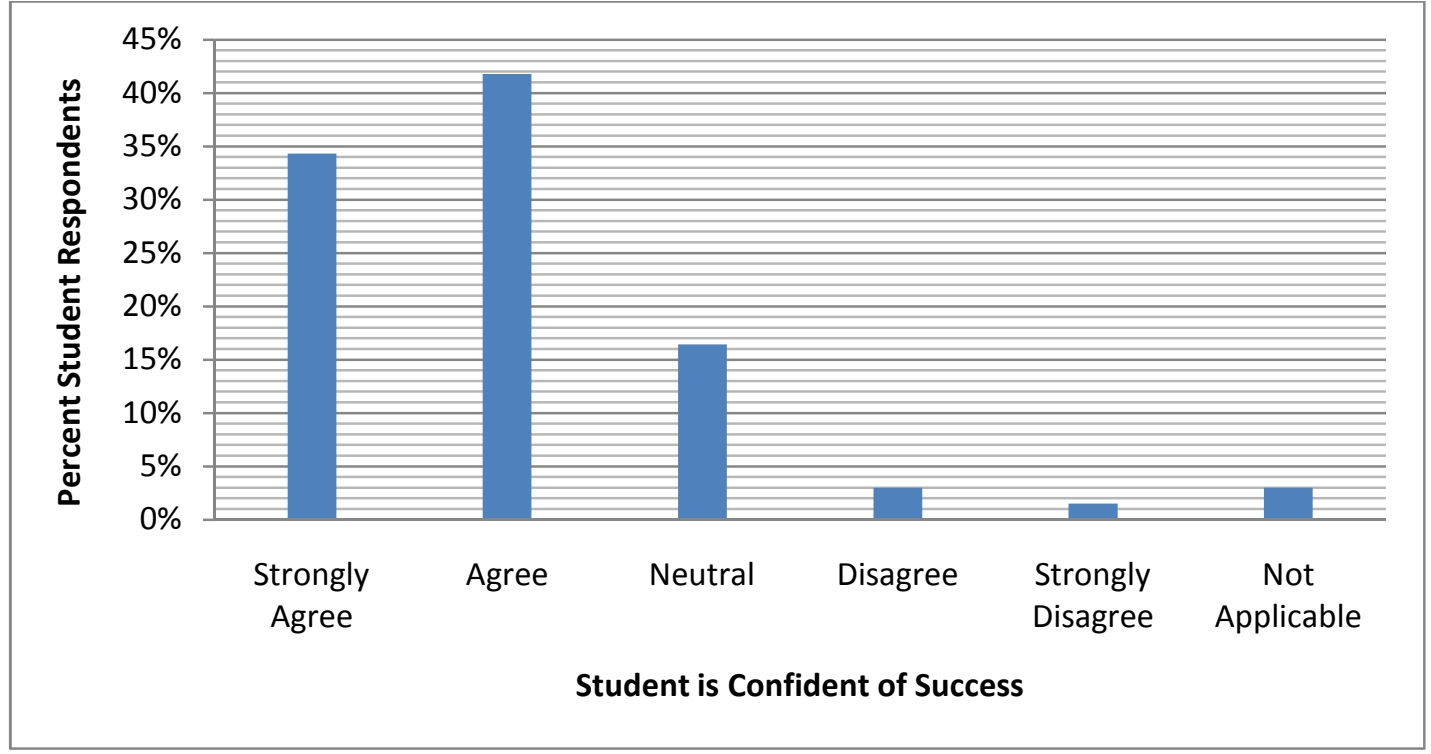

Figure 6: Student Success Self-Assessment Survey Results 


\section{Future Work}

Whereas the modifications to Principles of Aerospace Engineering can be immediately implemented, the true efficacy of these efforts to increase retention rates must be evaluated over the next few years. The success of the changes will be gauged using two means. Qualitatively, senior exit interview responses about the impact of AERO 101 from current graduates and upperclassmen will be compared to those of the freshman class (upon graduation). Furthermore, students that choose to leave the department will be surveyed and/or interviewed as to how AERO 101 may have played a part into their decision. These results will allow faculty to evaluate the course from a student perspective and to further refine improvements to the course. Quantitatively, the retention rates of the fall 2010 and future freshman classes will be compared to those of classes that completed the former version of the course. Also, because AERO 101 is not a mandatory course or prerequisite, retention rates from the freshman to sophomore year of students who do not take the course (control group) will be compared to those of students that do take the course. Here, the likelihood of students to both choose to take AERO 101 and continue in the department to graduation will be taken into account. These measures will provide a means of studying correlation between the changes in the course and retention rates. Preliminary results from the 2009-2010 and 2010-2011 freshman classes will be presented at the 2011 ASEE conference.

\section{Conclusions}

Several changes in the freshman introductory course Principles of Aerospace Engineering (AERO 101) have been implemented to focus on the student experience and encourage enthusiasm for the aerospace engineering profession. The motivation for these changes is the desire to retain students in the department from the freshman to the sophomore year.

Whereas the course once consisted of a one-way dissemination of information in a seminar format, the course now utilizes teams, mentors, assignments, tours, and guest lectures from current faculty, current students, and former students to engage students and encourage them to feel connected to the aerospace community. Based on semester-end student survey results, the changes to the course initially appear to effectively accomplish the goals of engaging the students and increasing their connectedness to the department. To evaluate if the course modifications ultimately impact retention rates, comparison of the retention rates of this class and future freshman classes to those of earlier graduating classes, as well as comparison to a control group that does not take AERO 101, is necessary. However, the initial attitudinal results give encouragement that Principles of Aerospace Engineering will positively impact the retention of students to the sophomore year.

\section{References}

1. Taylor S. B., Nutter, D. W., Davis, J.A. and Rencis, J. J., "Freshman Retention Study in Mechanical Engineering at the University of Arkansas," Proceedings of the 2005 Midwest Section Conference of the American Society for Engineering Education, University of Arkansas, Sept. 14-16, 2005.

2. Anderson-Rowland, M.R., "Understanding Freshmen Engineering Student Retention through a Survey," Annual Conference Proceedings, American Society for Engineering Education, Milwaukee, Wisconsin, June 1997. 
3. Committee on Prospering in the Global Economy of the 21st Century, "Rising Above the Gathering Storm: Energizing and Employing America for a Brighter Economic Future," Washington, D.C., 2007, p. 327.

4. Commission on the Future of the United States Aerospace Industry, Arlington, VA, November 2002, pp. v-xv.

5. U.S. Department of Labor, Employment and Training Administration, "America's Aerospace Industry: Identifying and Addressing Workforce Challenges", Washington, DC, May 2005, pp. 3-5.

6. Ohland, M.W., Sheppard, S.D., Lichtenstein, G., Eris, O., Chachra, D, and Layton, R.A., "Persistence, Engagement, and Migration in Engineering Programs," Journal of Engineering Education, Vol. 97(3), July 2008, pp. 259-278. 


\section{Appendix}

This section includes two actual assignments used in Principles of Aerospace Engineering.

\section{Assignment: Materials \& Structures in Aerospace}

The purpose of this assignment is to help you better understand the impact of materials and structures in current aerospace projects.

- Individually read the following articles and explanations of the new Boeing 787 Dreamliner: http://www.designnews.com/article/14313-

Boeing_787_Dreamliner_Represents_Composites_Revolution.php

http://www.seattlepi.com/boeing/787/787primer.asp

http://www.dailyfinance.com/story/company-news/is-boeing-s-787-safe-to-fly/19076555/

http://www.newairplane.com/787/

- Discuss the following questions with your team. Individually summarize your team's answers.

1. How is the Boeing 787 different from other aircraft, in terms of materials and structures?

2. Why is Boeing using these new materials?

3. What are some improvements to the inside of the aircraft?

4. What are the challenges and safety concerns with the Boeing 787 ?

Bonus Questions

- Read the following:

http://seattletimes.nwsource.com/html/boeingaerospace/2013073872_787faa05.html

http://online.wsj.com/article/SB10001424052748703843804575535191275956762.html

5. What might be an unintended consequence of the 787 wing design? How might this impact the cost of air travel for airlines using the 787 ?

- From the Career Preparation assignment, most of you noted that Lockheed Martin \& Boeing had locations in nearly every state.

6. Why might these companies want a location in every state? Who is one of their biggest clients and how might company locations factor into this client's decisions? 


\section{Assignment: Career Preparation}

The purpose of this assignment is to familiarize you with the Career Fair and other services available at a large, public university to help you (eventually) find an internship, co-op, or fulltime job.

\section{The Career Fair is: (Dates, Hours, Location)}

- First, go to the Career Fair website (sec.tamu.edu) and Career Center website (careercenter.tamu.edu).

- Answer the following questions:

1. Do all companies attend both days? How might this impact your plans if you would like to talk to recruiters from a specific company?

2. What transportation is available to the Career Fair? What must a student present to be admitted to the Career Fair?

3. What is the dress for the Career Fair? What are some examples of this type of dress?

4. List at least 20 companies that hire AERO majors that will be attending the Career Fair. Hint: Use the Company Search on the Career Fair website.

a. Choose 3 of these companies.

b. Search online for the website of each company and note the URL of the site.

c. Browse the company websites to find the following information for each of the three companies:

i. At what locations might you live if you worked for this company?

ii. In what AERO disciplines does this company specialize?

iii. What types of work/projects might I do at this company?

d. Attend Career Fair and find the booths of these three companies. Observe how upperlevel students interact with their potential employers and look for informational flyers for companies for which you are interested in work.

Note: You are not required to talk to recruiters for this assignment.

5. What services does the Career Center offer that might be helpful?

6. Where might you find additional resources about AERO careers within the aerospace engineering department? 